\title{
Cinco odas de Horacio
}

\author{
Ramón IrigoYen
}

Limitándonos sólo a España, muchos son los traductores que han asesinado a Horacio, con más o menor amor, según los casos, pero el crimen, indefectiblemente, aun en el caso de Fray Luis de León, siempre se ha perpetrado. Por supuesto que no todos los homicidios del poeta de Venusa se merecen la misma sentencia y un tribunal no excesivamente severo acaso hasta podría absolver a algún que otro traductor en alguno de sus intentos (el mismo Fray Luis de León, el más horaciano de nuestros poetas clásicos, como Francisco Brines lo es de nuestros poetas contemporáneos, consiguió algunas traducciones aceptables, con alguna que otra estrofa incluso excelente, siempre y cuando uno no se acuerde mucho del original). Pero, en su mayoría, las traducciones españolas de Horacio son deplorables. El mismo Menéndez y Pelayo, que conocía prácticamente todo lo que se había traducido de Horacio en España, refiriéndose a las traducciones de la obra completa del autor de las Odas (las versiones de Villén de Biedma, del P. Urbano Campos y la de Joaquín Escriche), aseguraba «que quien no sea erudito o latinista (y mucho menos quien lo sea, porque éste no necesita traducciones), no podrá leer seguidas dos páginas, sin dormitar y dejar caer el libro de las manos». Mejor opinión le merecía a Menéndez Pelayo otra versión de la obra de Horacio la de Javier de Burgos, llegando a considerarla «trabajo ciertamente de primer orden, 
digno de ponerse al lado de los mejores que otras naciones ostentan». Pero en este juicio de Menéndez Pelayo sobre la traducción de Javier de Burgos hay excesivo optimismo y ya Andrés Bello, el poeta y crítico venezolano, llamaba a Burgos «mal traductor y excelente comentador de Horacio».

De las traducciones modernas de Horacio al castellano no he podido ver la de Cejador y Frauca, publicada en Madrid en 1927 (Horacio, fiel y delicadamente vuelto en lengua castellana). La de Chamorro, Odas y épodos (sic), publicada por el C.S.I.C. en 1951 y reeditada en la Colección Austral de Espasa-Calpe, es otro intento frustrado de traducción. La de Lorenzo Riber, publicada por Aguilar, es una traducción pedestre, pero bastante útil para desentrañar algunas de las dificultades de los poemas originales. Por cierto que estas pedestres traducciones horacionas de Lorenzo Riber nos evidencian una vez más la dificultad de traducción de la poesía, pues el mismo traductor realizó una excelente versión de las obras en prosa de Séneca (la traducción de las Tragedias no es tan buena) y también excelente es su versión de las Confesiones y de los cinco primeros libros de La Ciudad de Dios de San Agustín.

Mejor es no acordarse de la traducción de la obra de Horacio preparada por Germán Salinas. Publicada por EDAF, está a la altura de las ediciones de clásicos arrojadas al mercado por esta editorial y, por tanto, plagada de errores y mal gusto. Tampoco las Odas (selección) editadas por R. Torner en Gredos aportan nada decisivo.

Las Poesias escogidas de Horacio traducidas por López Soto y publicadas por Bruguera en 1974 resultan algo más legibles que la mayoría de las traducciones citadas.

Enrique Badosa tiene anunciadas como de próxima publicación Treinta odas de Horacio que no sé si han sido editadas.

¿Cuándo tendremos por fin una traducción de Horacio equiparable a la excelente que del Satiricón nos dio Díaz y Díaz, o como la de las Comedias de Terencio editadas por Lisardo Rubio, o La Guerra Civil editada por Mariner y una docena más de textos latinos que a lo sumo se pueden citar? 
Tras tantos fracasos de traducción, nadie podrá pensar que presento la versión de estas cinco odas con optimismo. Y, naturalmente, el fracaso de tantos predecesores míos no palia la tristeza por mi propio fracaso, pues si tantas traducciones antiguas de Horacio han sido verdaderos asesinatos, las modernas son más condenables, por haber degenerado en la rutina y trivialización del crimen. $\mathrm{Y}$, sin embargo, en algunos momentos de acaso excesivo optimismo uno quiere creer con el poeta Jaime Gil de Biedma que, si su traducción es insatisfactoria, al menos se libró de esa facha de hospiciano tan frecuente en nuestras traducciones españolas.

El texto latino es el establecido por F. Villeneuve para la Colección Budé de Les Belles Lettres (Paris, sexta edición, 1959). 
Od. I, 9

Vides ut alta stet niue candidum

Soracte nec iam sustineant onus siluae laborantes geluque

flumina constiterint acuto?

Dissolue frigus ligna super foco

large reponens atque benignius

deprome quadrimum Sabina,

o Thaliarche, merum diota.

Permitte diuis cetera, qui simul

strauere uentos aequore feruido

deproeliantis, nec cupressi

nec ueteres agitantur orni.

Quid sit futurum cras, fuge quaerere, et

quem fors dierum cumque dabit, lucro

adpone nec dulcis amores

sperne, puer, neque tu choreas,

donec uirenti canities abest

morosa. Nunc et Campus et areae

lenesque sub noctem susurri

composita repetantur hora,

nunc et latentis proditor intumo

gratus puellae risus ab angulo

pignusque dereptum lacertis

aut digito male pertinaci.

\section{Od. $I, 11$}

Tu ne quaesieris (scire nefas) quem mibi, quem tibi finem di dederint, Leuconoe, nec Babylonios temptaris numeros. Vt melius quicquid erit pati! Seu pluris hiemes seu tribuit Iuppiter ultimam, quae nunc oppositis debilitat pumicibus mare Tyrrhenum, sapias, uina liques et spatio breui spem longam reseces. Dum loquimur, fugerit inuida aetas: carpe diem, quam minimum credula postero. 
¿Ves cómo el Soracte se alza blanco de espesa

nieve y ya los bosques agobiados no pueden sostener

su carga y los ríos se han detenido

bajo la cruda helada?

Pon iin al frío echando al fuego leña

en abundancia y de ánfora sabina de doble asa

saca, Taliarco, con largueza

vino de cuatro años.

Deja a los dioses lo demás, que desde que abaticron

a los vientos que en el bullente mar

luchaban, ya ni los cipreses

ni los viejos fresnos se menean.

Evita indagar lo que será el mañana

y el día que el azar te depare, sea cuando sea,

ponlo en tu haber, y los dulces amores no desdeñes,

muchacho, ni tampoco las danzas,

mientras que en tu lozanía aún está lejos la penosa

vejez. Ahora ha de acudirse al Campo de Marte

y a las plazas y han de buscarse esos murmullos leves

a la hora convenida, hacia el anochecer

y ahora también la deleitosa risa que traiciona

a tu muchacha oculta en íntimo rincón

y esa prenda de amor que ella se quita de los brazos

o de un dedo que apenas se resiste.

\section{Od. I, 11}

Tú no indagues (sacrilegio es saberlo) qué límite, Leucónoe, los dioses han fijado para ti, y para mí, ni consultes la astrología babilónica. ¿Cuánto más vale sufrir cualquier azar!

Ya te conceda Júpiter más de un invierno, o éste sea el último, el que ahora quebranta al mar Tirreno en la barrera

de los acantilados, sé cuerda, filtra tus vinos y para un lapso tan corto cercena a la esperanza sus excesos. Mientras hablamos, celoso habrá huido el tiempo: goza el día de hoy, y no te fíes nada del mañana. 
Od. II, 14

Eheu fugaces, Postume, Postume.

labuntur anni nec pietas moram

rugis et instanti senectae

adferet indomitaeque morti,

non, si trecenis quotquot eunt dies,

amice, places inlacrimabilem

Plutona tauris, qui ter amplum

Geryonen Tityonque tristi

compescit unda, scilicet omnibus

quicumque terrae munere uescimur

enauiganda, siue reges

siue inopes erimus coloni.

Frustra cruento Marte carebimus

fractisque rauci fluctibus Hadriae,

frustra per autumnos nocentem

corporibus metuemus Austrum:

uisendus ater flumine languido

Cocytos errans et Danai genus

infame damnatusque longi

Sisyphus Aeolides laboris.

Linquenda tellus et domus et placens uxor, neque harum quas colis arborum

te praeter inuisas cupressos

ulla breuem dominum sequetur;

absumet heres Caecuba dignior

seruata centum clauibus et mero

tinguet pauimentum superbo,

pontificum potiore cenis. 
Od. $I I, 14$

Ay, Póstumo, Póstumo, fugaces

se deslizan los años y tu piedad no hará que se retrasen

las arrugas, la vejez inminente

y la muerte invencible,

no, ni aun cuando, amigo, cada día que pase,

inmoles tú trescientos toros

al inexorable Plutón, que aprisiona

a Ticio y al tres veces fuerte Gerión

en sus fúnebres aguas que nosotros, sí, todos

cuantos de los dones de la tierra nos nutrimos

hemos de atravesar, seamos reyes

$o$ indigentes labriegos.

En vano nos guardaremos del sangriento Marte y de las olas rotas del rugiente Adriático,

en vano, en los otoños, huiremos del Austro

que daña a nuestros cuerpos:

hemos de visitar el negro Cocito que se arrastra con lánguida corriente y a la infame

prosapia de Dánao y a Sísifo, hijo de Eolo, condenado a un trabajo sin fin.

Hay que dejar la tierra y la casa y la mujer que nos deleita, y de estos árboles que cuidas, salvo los odiosos cipreses,

a ti, su dueño efímero, ninguno ha de seguirte.

Un sucesor más digno consumirá el cécubo

que tú bajo cien llaves has guardado y bañará

el pavimento con el soberbio vino,

que para sus banquetes quisieran los pontífices. 
Od. III, 9

«Donec gratus eram tibi

nec quisquam potior bracchia candidae

ceruici iuuenis dabat,

Persarum uigui rege beatior.»

«Donec non alia magis

arsisti neque erat Lydia post Chloen, multi Lydia nominis,

Romana uigui clarior Ilia.»

«Me nunc Thressa Chloe regit,

dulcis docta modos et citharae sciens, pro qua non metuam mori, si parcent animae fata superstiti.»

«Me torret face mutua

Thurini Calais filius Ornyti, pro quo bis patiar mori,

si parcent puero fata superstiti.»

«Quid si prisca redit Venus

diductosque iugo cogit aeneo, si flaua excutitur Chloe

reiectaeque patet ianua Lydiae?»

«Quamquam sidere pulchrior

ille est, tu leuior cortice et inprobo iracundior Hadria,

tecum uiuere amem, tecum obeam lubene.» 


$$
\text { Od. III, } 9
$$

- Mientras yo te agradaba

y ningún muchacho, favorito tuyo, anudaba sus brazos

a tu radiante cuello,

más que el rey de los persas fui dichoso.»

- «Y mientras tú no te abrasaste más por otra, y Lidia no venía tras tu Cloe,

yo, Lidia, la de inmenso renombre,

fui más famosa que Ilia la Romana.»

- «A mí me manda ahora una tracia, Cloe,

sabia en dulces acordes y virtuosa de la cítara,

por quien morir no temería,

si a ella, mi alma, respetaban los hados, y me sobrevivía.»

- «Con recíproco fuego me socarra

Calais, hijo de Órnito de Turio,

por quien dos muertes sufriría yo,

si al muchacho los hados respetaban, y me sobrevivía.»

- ¿¿ $Y$ qué tal si retorna aquel amor de antaño y nos reúne con su broncíneo yugo tras nuestra desunión,

y si, tras arrojar de mí a la rubia Cloe,

a la Lidia que repudié abro mis puertas?»

— «Aunque él es más hermoso

que un lucero, y tú eres más ligero que el corcho

y aun más irritable que el sañudo Adriático,

vivir quiero contigo y yo contigo moriría a gusto.» 


\section{Od. $I V, 7$}

Diffugere niues, redeunt iam gramina campis arboribusque comae;

mutat terra uices et decrescentia ripas flumina praetereunt;

Gratia cum Nymphis geminisque sororibus audet ducere nuda choros.

Inmortalia ne speres, monet annus et almum quae rapit hora diem.

interitura simul

pomifer autumnus fruges effuderit, et mox bruma recurrit iners.

Frigora mitescunt Zephyris, uer proterit aestas,

Damna tamen celeres reparant caelestia lunae: nos ubi decidimus

quo pater Aeneas, quo diues Tullus et Ancus, puluis et umbra sumus.

Quis scit an adiciant hodiernae crastina summae tempora di superi?

Cuncta manus auidas fugient heredis, amico quae dederis animo.

Cum semel occideris et de te splendida Minos fecerit arbitria,

non, Torquate, genus, non te facundia, non te restituet pietas;

infernis neque enim tenebris Diana pudicum liberat Hippolytum,

nec Lethaea ualet Theseus abrumpere caro uincula Pirithoo. 
Las nieves se han marchado, los céspedes ya vuelven a los campos, las frondas a los árboles;

la tierra cambia de estación y en su mengua los ríos

discurren por sus cauces;

la Gracia con las Ninfas y con sus dos hermanas desnuda osa guiar sus danzas.

Nada inmortal esperes, te lo advierte el año y la hora que nos arrebata el almo día.

Los fríos se apaciguan con las brisas, a la primavera la arrolla el verano, que ha de morir en cuanto

derrame sus dones el frutal otoño, y pronto regresa el yerto invierno.

Pero al menos las lunas reparan pronto los daños de los cielos: mas nosotros cuando caemos

en donde nuestro padre Eneas, en donde el rico Tulo y Anco, somos ya polvo y sombra.

¿Quién sabe si los dioses celestiales al total del día de hoy añadirán las horas de mañana?

Escapará a las manos codiciosas del heredero todo lo que a ti mismo amistosamente te regales.

Una vez que hayas muerto y sobre ti haya emitido Minos su augusta sentencia,

ni tu origen, Torcuato, ni tu labia, ni tu piedad te van a devolver la vida;

pues ni Diana de las tinieblas infernales libera al casto Hipólito,

ni es capaz Teseo de romper las cadenas leteas de su querido Piritoo. 
